\title{
Utilização dos subprodutos da fresagem do osso subcondral em substituição ao enxerto autólogo esponjoso em artrodeses de carpo de cães
}

\author{
Subproducts of subchondral bone fraising in substitution of autologous cancellous grafts in \\ pancarpal arthrodesis of dogs
}

\author{
Cássio Ricardo Auada Ferrigno ${ }^{\mathrm{I}}$ Alexandre Schmaedecke ${ }^{\mathrm{II}}$ \\ Vanessa Couto de Magalhães Ferraz ${ }^{\mathrm{I}}$
}

\section{RESUMO}

\begin{abstract}
A artrodese rádio-cárpica é procedimento radical usado no tratamento de fraturas e luxações do carpo, com danos à fibrocartilagem palmar e às estruturas ligamentares de sustentação, decorrentes de hiperextensão. Para este estudo foram selecionados 15 cães, submetidos à artrodese rádiocárpica, entre abril/02 e julho/04. Foram estudados os casos quanto à formação de calo ósseo e às complicações póscirúrgicas. A técnica consistiu na ostectomia da superfície articular do rádio, expondo-a e retificando-a. Os subprodutos desta fresagem foram reintroduzidos como enxerto após sua redução em tamanho com rugina. Para a estabilização articular, em todos os casos, foram usadas placas compressivas. Foram realizados exames radiográficos imediatamente à intervenção cirúrgica e em intervalos de 30 dias, até a total fusão articular. Os resultados obtidos neste estudo, com fusão da articulação em até 300 dias de pós-cirúrgico em $80 \%$ dos casos estudados, foram semelhantes aos dispostos para as técnicas que utilizam enxertos autólogos esponjosos, sendo que, em $68 \%$ dos pacientes, a recuperação se deu sem qualquer complicação significativa. Pequenas complicações, como o aumento de volume, foram observadas em $22 \%$ dos casos, não determinando qualquer alteração no resultado final. Tais resultados viabilizam a técnica descrita, demonstrando a exeqüibilidade da utilização dos subprodutos da fresagem do osso subcondral como enxerto em artrodeses de carpo em cães.
\end{abstract}

Palavras-chave: artrodese do carpo, enxertos, cães.

\section{ABSTRACT}

Pancarpal arthrodesis is an extreme procedure, used in the treatment of fractures and carpal luxations, with damage to the palmar fibro cartilage and structural ligaments, after hyperextension. For this study 15 dogs were selected, which underwent pancarpal artrodesis, betwen April/ 2002 and
July/2004. The cases were studied in regard to bone formation and post-surgical complications. The technique consisted in the ostectomy of the articular surface of the radius, exposing and rectifying it. The byproducts of this reaming were introduced as a graft after their size reduction, with a grinder. In all cases, compressive plates were used for the articular stabilization. Immediately after surgery, radiographic exams were made and in 30 days intervals, until complete articular fusion. The results from this study, with articular fusion before 300 days after surgery in $80 \%$ of the cases, were extremely similar to the ones observed with techniques that use autologous cancellous bone grafts, and $68 \%$ of the patients recovered without significant complications. Small complications like slight swelling were observed in $22 \%$ of the cases, not determining any alterations in the final result. These results show that the technique is viable, demonstrating the possibility of use of the byproducts of subchondral bone reaming as a graft in the arthrodesis of dogs.

Key words: pancarpal arthrodesis, bone grafts, dogs.

\section{INTRODUÇÃO}

A artrodese rádio-cárpica é procedimento radical usado principalmente no tratamento de fraturas e luxações ou subluxações do carpo, com conseqüentes danos tanto à fibrocartilagem palmar quanto às estruturas ligamentares de sustentação, decorrentes de hiperextensão (JOHNSON,1980; DENNY \& BARR.,1991; LI et al.,1999; WHITELOCK et al.,1999; GUILLIARD \& MAIO, 2001). As lesões descritas são geralmente provocadas por quedas, exercícios incorretos ou trauma direto, gerando injúria aos tecidos moles palmares e resultando em claudicação, dor e

'Departamento de Cirurgia, Faculdade de Medicina Veterinária e Zootecnia, Universidade de São Paulo (FMVZ/USP), São Paulo, SP, Brasil.

"Faculdade de Medicina Veterinária, Universidade Federal do Paraná (UFPR), PR, Brasil. Endereço para correspondência: Av. Profº Orlando Marques de Paiva, 87, Cidade Universitária, 05508 900, São Paulo, SP, Brasil. E-mail: alexsvet@usp.br. 
osteoartrite do carpo (WILLER et al., 1990; GUILLIARD \& MAIO, 2001, TOMLIN et al., 2001).

WILLER (1990) e RALPHS et al. (2000) citaram o uso da técnica na correção de lesões cárpicas imuno-mediadas, como nos casos de poliartrite erosiva idiopática, também denominada artrite reumatóide, tendo esta doença uma predisposição por raças pequenas e gerando perda de espaço articular, erosão da cartilagem, osteofitose, com luxação ou subluxação da articulação afetada e formação de fibrose dos tecidos adjacentes.

A técnica cirúrgica empregada para artrodese consiste, segundo DENNY \& BARR (1991), em um acesso iniciando pela face medial do terço final do rádio, seguindo em uma curva para a região médiolateral do metacarpo distal. Afastando-se lateralmente a pele e os tendões extensores digitais do carpo, podese observar o carpo em sua face dorsal. Os tendões de inserção do músculo carpo-radial, na face proximal do segundo e terceiro metacarpeanos, são elevados e rebatidos para ampla visualização da área. A cápsula articular é então removida, na região dorsal do carpo, sendo neste momento a articulação flexionada e, com auxílio de serra oscilatória ou de um pequeno osteótomo, retirada a cartilagem articular do carpo.

Para a artrodese, é indicada uma placa de compressão dinâmica de 2,7 ou 3,5mm (JOHNSON, 1980; DENNY \& BARR.,1991; RALPHS et al., 2000; MICHAL et al., 2003), podendo, em certos casos, ser utilizada até uma placa de 4,5mm (DENNY \& BARR,1991). Com relação à técnica de utilização de placas, DENNY \& BARR (1991) indicaram a necessidade de, no mínimo, sete parafusos de fixação, sendo um no osso carpo radial, três no terceiro metacarpeano e, no mínimo, três no segmento distal do rádio.

Em estudo retrospectivo realizado por DENNY \& BARR (1991), 56 artrodeses foram realizadas em 50 animais, sendo 43 procedimentos totais e dez parciais do carpo, tendo apontado um quadro de recuperação total da função do membro em 76\% dos animais tratados com artrodese total e em apenas 50\% dos tratados com procedimento parcial.

Em outro estudo, LI et al. (1999) utilizaram a artrodese total do carpo no tratamento de 11 cães, com peso variando entre $15 \mathrm{~kg}$ e $38 \mathrm{~kg}$, perfazendo 13 procedimentos, utilizando uma placa de compressão dinâmica híbrida de 2,7/3,5mm. Setenta e sete por cento dos animais tratados não apresentaram nenhuma complicação pós-operatória com retorno à atividade funcional do membro em até oito semanas após a intervenção.

Como preenchimento do espaço articular, DENNY \& BARR (1991) e MICHAL et al. (2003) descreveram a utilização de enxerto autólogo esponjoso, colhido do úmero ou da asa do ílio. No entanto, citam como desvantagem a necessidade de formação de um novo sítio cirúrgico e aumento do tempo operatório.

As principais complicações da artrodese são indicadas pela fratura dos ossos do metacarpo, decorrentes de uma fixação inadequada da placa, com excessiva pressão sobre estes. Para evitar este quadro, LI et al. (1999) descreveram que a mesma deve cobrir uma área superior a um terço do metacarpo, sendo que WHITELOCK et al. (1999) indicam cobertura de 50\% do metacarpo. Outro fator que aumenta a tensão sobre os metacarpeanos é a angulação natural dos mesmos em relação ao rádio o que pode, segundo LI et al. (1999) e MICHAL et al. (2003), ser minimizado ao se promover uma angulação na placa em cerca de 10 graus. Já DENNY \& BARR (1991) descreveram este procedimento como facultativo. LI et al. (1999) citaram ainda um fator de complicação transoperatório por conta do excesso de tensão da pele, resultante da pouca quantidade de tecidos moles para fechamento da incisão por sobre uma placa de 3,5mm. Quando da utilização de placas de 2,7mm, a complicação se dá em termos da diminuição de rigidez oferecida pela placa em relação à anterior. Como solução, neste caso, os mesmos indicaram o uso da placa híbrida 2,7/3,5mm. Em casos onde se faz necessária a intervenção cirúrgica bilateral, o tempo mínimo de intervalo entre cada procedimento é, segundo DENNY \& BARR (1991), de cinco semanas.

O objetivo deste estudo foi avaliar clínica e radiograficamente a fusão articular após artrodese rádiocárpica utilizando, no espaço articular, os subprodutos da fresagem do osso subcondral em substituição ao enxerto autólogo esponjoso.

\section{MATERIAL E MÉTODOS}

Foram selecionados 15 cães, machos e fêmeas, de diferentes raças, com lesões decorrentes de luxação ou hiper-extensão (Figura 1), que foram submetidos à artrodese rádio-cárpica no Serviço de Cirurgia de Pequenos Animais do Hospital Veterinário da Universidade de São Paulo, no período de abril de 2002 a julho de 2004. Foram estudados os casos quanto a raça, idade, peso, sexo, tipo de artrodese (tamanho da placa e quantidade de parafusos), formação de calo ósseo na articulação e complicações pós-cirúrgicas.

Após o preparo rotineiro de campo operatório, foi iniciado o procedimento cirúrgico com abordagem médio-cranial, na região do rádio, estendendo-se a incisão para a face cranial do membro após atingir a articulação rádio-cárpica, chegando até os metacarpos. Após a identificação do espaço articular da articulação rádio-cárpica, e secção da cápsula articular, em 12 articulações, foram promovidas a 


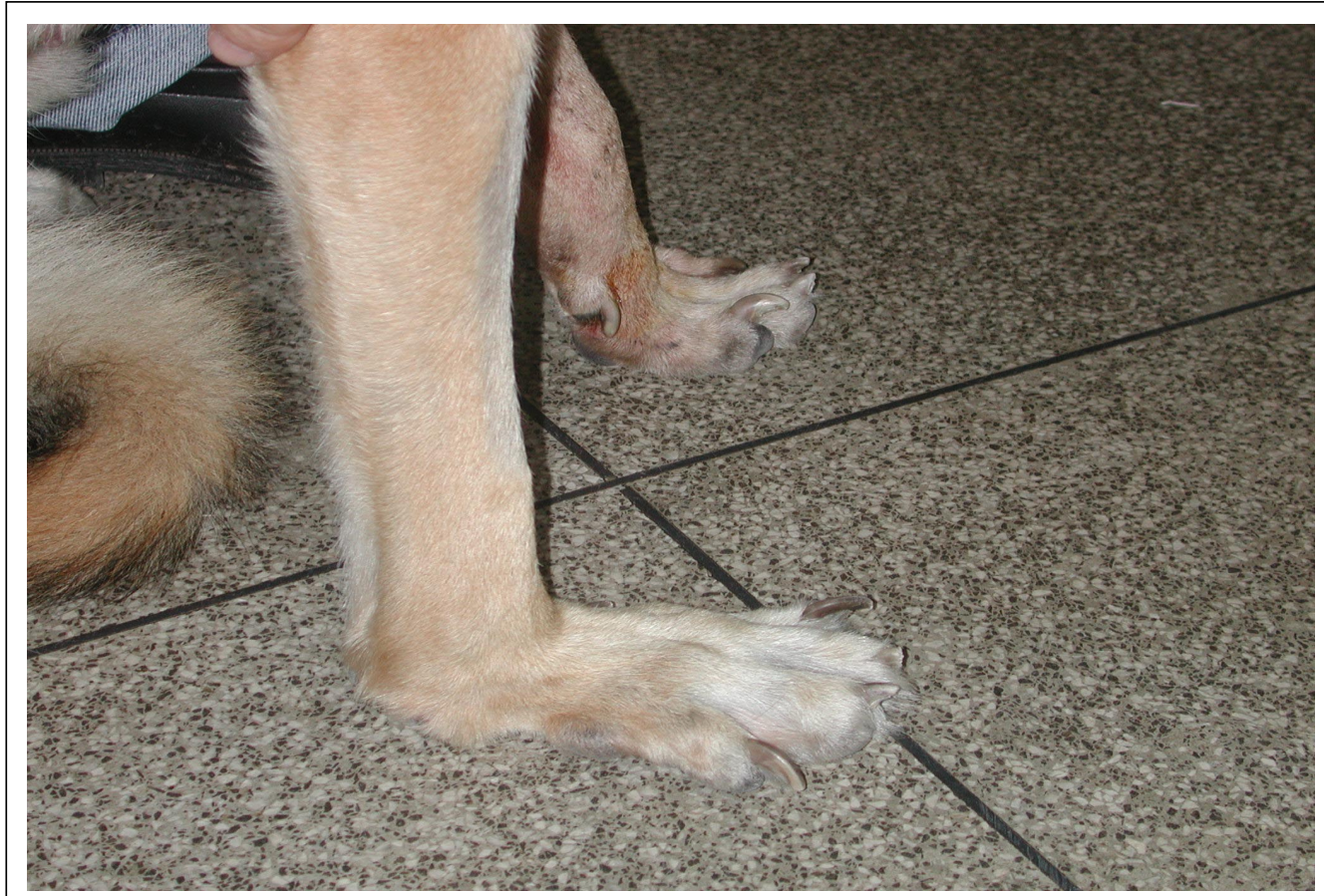

Figura 1 - Imagem fotográfica de articulação rádio-cárpica direita de cão apresentando hiperextensão articular, submetido posteriormente à artrodese.

osteotomia da superfície articular do rádio com serra óssea pneumática a fim de retirar toda a cartilagem, expondo e retificando a superfície para a melhor artrodese (Figura 2). Em sete articulações, este procedimento foi realizado com broca e motor de baixa rotação. O procedimento de retirada da cartilagem foi considerado terminado quando não havia cartilagem evidente nem presença de sangramento do osso

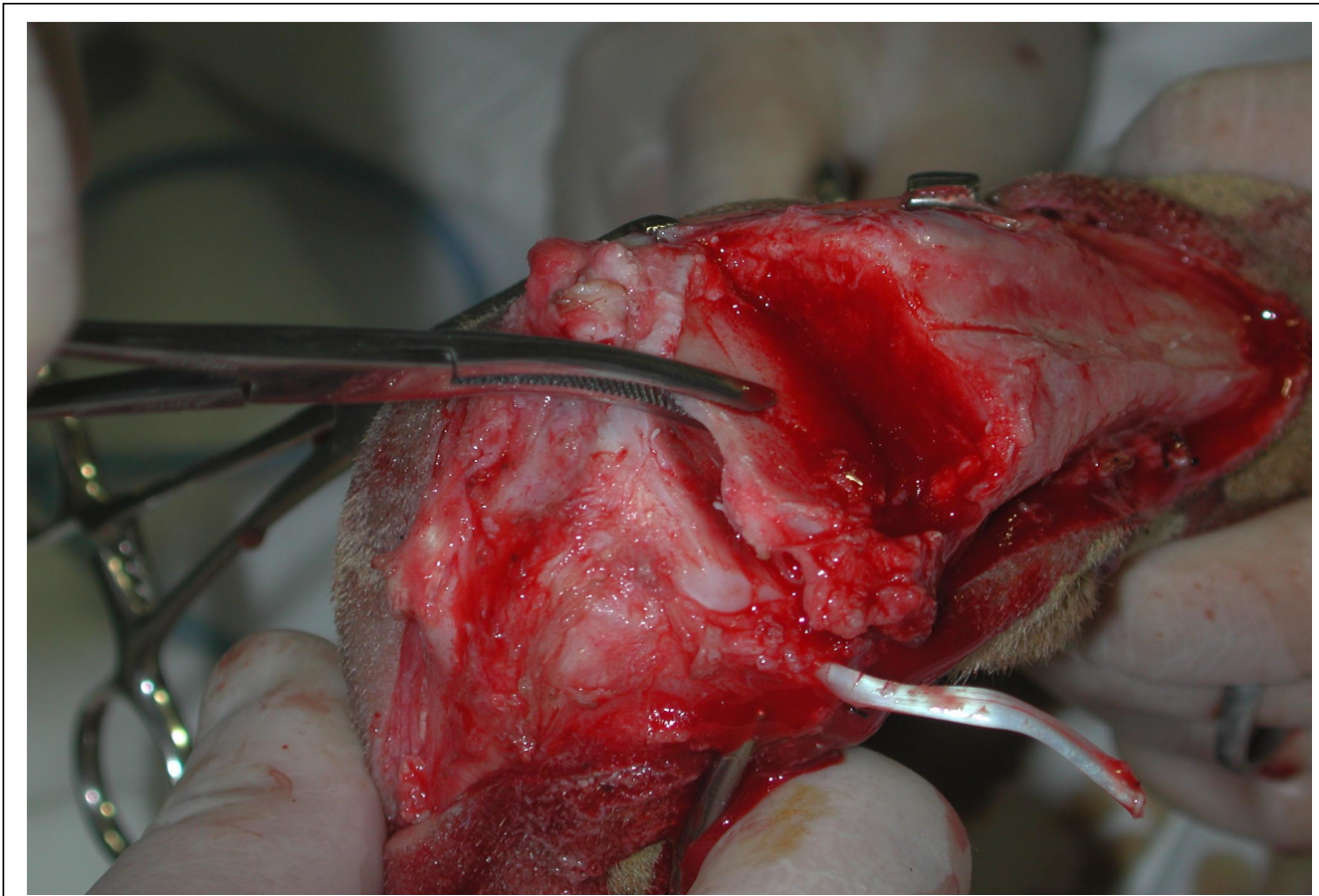

Figura 2 - Imagem fotográfica ilustrando momento da remoção da cartilagem articular e do osso subcondral para posterior fresagem e utilização como substituto ao enxerto autólogo esponjoso em cão. 
subcondral. Os subprodutos da fresagem ou da ostectomia foram utilizados como enxerto depois de serem reduzidos em tamanho com uma rugina e reintroduzidos no espaço articular.

Para a estabilização da articulação em todos os casos, foram usadas placas de aço compressivas de 3,5mm, de acordo com princípios básicos da $\mathrm{AO}$ "Arbeitsgemeinschaft für Osteosynthesefragen” (BRINKER et al., 1997) (Figura 3). Em dez articulações, foram usadas placas com 11 parafusos; em três articulações, placas com 13 parafusos; em duas articulações, placas com 10 parafusos; e, em quatro articulações, placas com sete parafusos, além de utilizar a passagem de dois parafusos compressivos de $4 \mathrm{~mm}$ de diâmetro entre o rádio e o carpo. Foram realizados exames radiográficos (Figuras 4 e 5) imediatamente após a intervenção cirúrgica e nos intervalos de 30, 60, 90, 180, 270 e 300 dias pós-cirúrgicos, ou até a total fusão óssea. Os exames radiográficos foram avaliados quanto à fusão da linha articular e foram atribuídas notas segundo o trabalho de MICHAL et al. (2003), sendo " 0 ” para ausência de tecido mineralizado no espaço articular, "1" para início de ponte óssea, mas com o espaço articular ainda visível, e "2” para presença de fusão sólida da articulação.

Os membros operados foram imobilizados com imobilização com calha de gesso sintético por seis semanas. Após este período, foram retiradas as imobilizações e recomendado repouso, com restrição de espaço para movimentação por mais seis semanas.

\section{RESULTADOS}

Em 11 dos 19 casos estudados (58\%), obteve-se fusão sólida da articulação em até 180 dias pós-cirúrgicos; em três casos (16\%), fusão sólida em até 270 dias; em três casos (16\%), em até 300 dias e, em dois casos (10\%), não houve fusão sólida da articulação em 300 dias pós-cirúrgicos. Com relação às complicações apresentadas durante o período póscirúrgico, os resultados apontam 13 casos (68 \%) sem complicação significativa, quatro casos (20\%) com formação de edema local ou impossibilidade de manutenção de calha gessada, classificados como mínima complicação, e dois casos (10\%) com exposição da placa durante o período de recuperação (Tabela 1).

\section{DISCUSSÃO}

Conforme descrito por JOHNSON (1980), DENNY \& BARR (1991), LI et al. (1999), WHITELOCK et al. (1999), GUILLIARD et al. (2001), a técnica de artrodese foi utilizada em pacientes com lesões decorrentes de quedas ou saltos de alturas

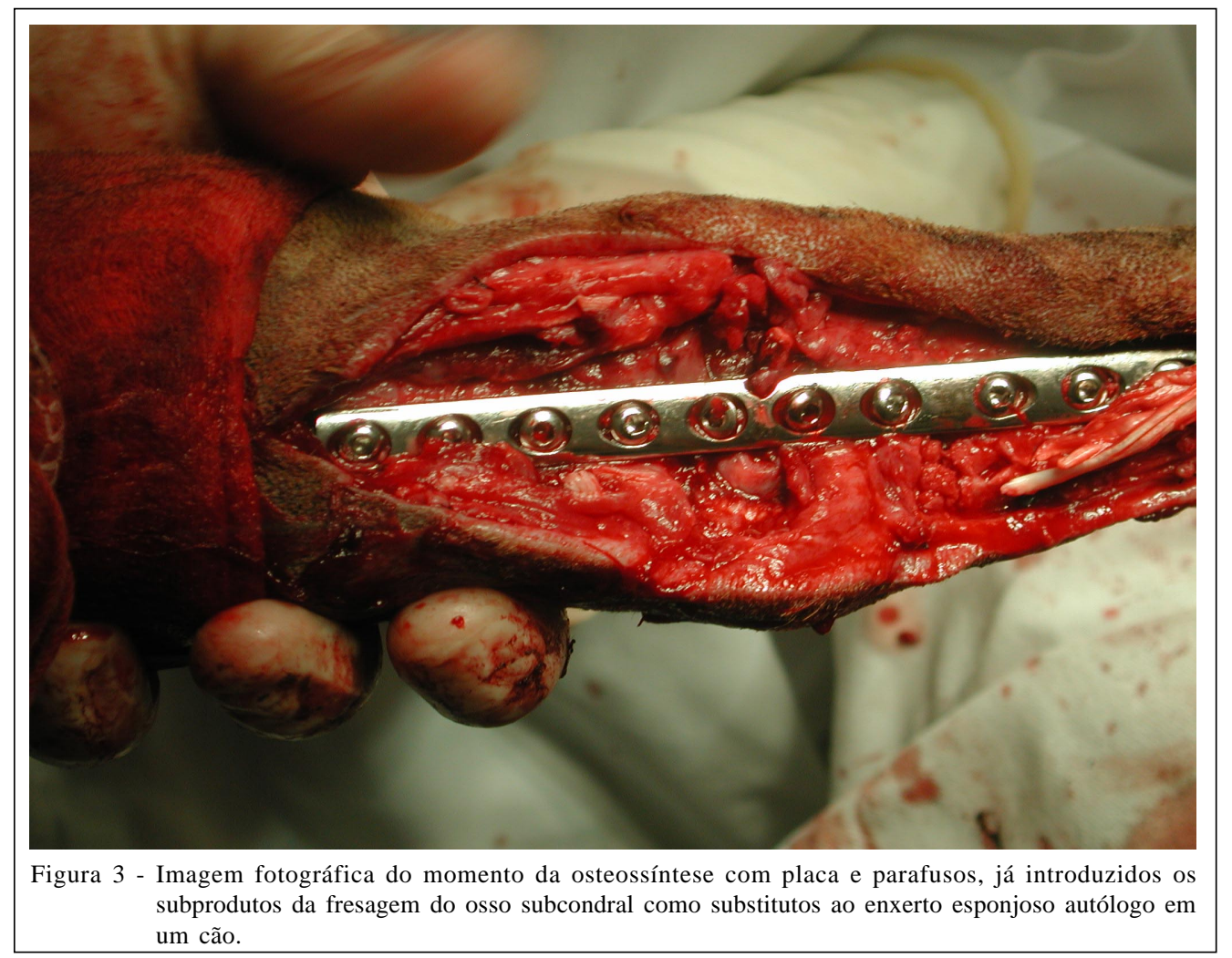

Ciência Rural, v.38, n.2, mar-abr, 2008. 


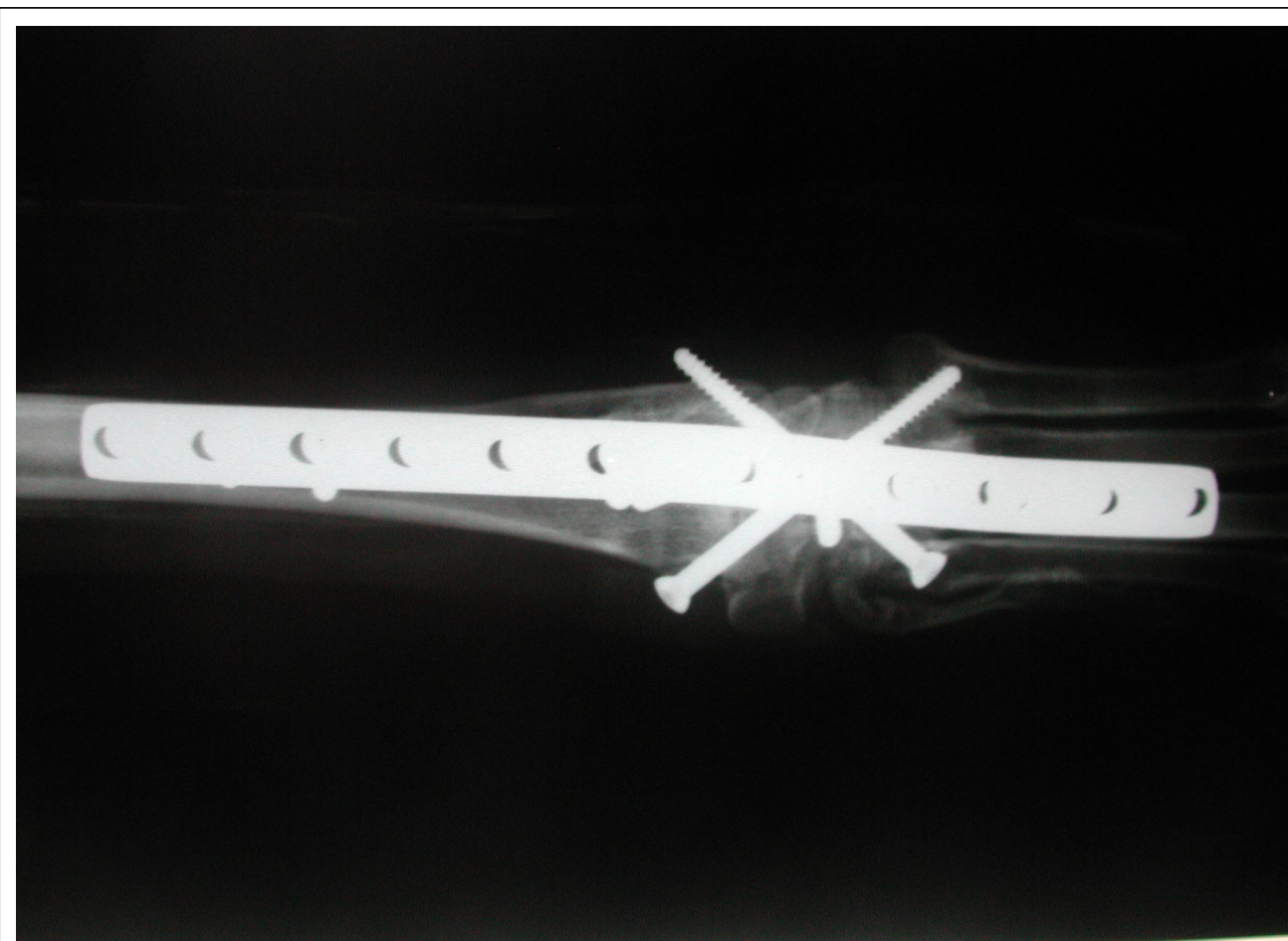

Figura 4 - Imagens fotográficas de radiografias em projeções médio-lateral e dorso-palmar, 30 dias após intervenção cirúrgica. Nota-se a presença de dois parafusos cruzados de $4,5 \mathrm{~mm}$ de diâmetro, produzindo maior estabilidade do implante.

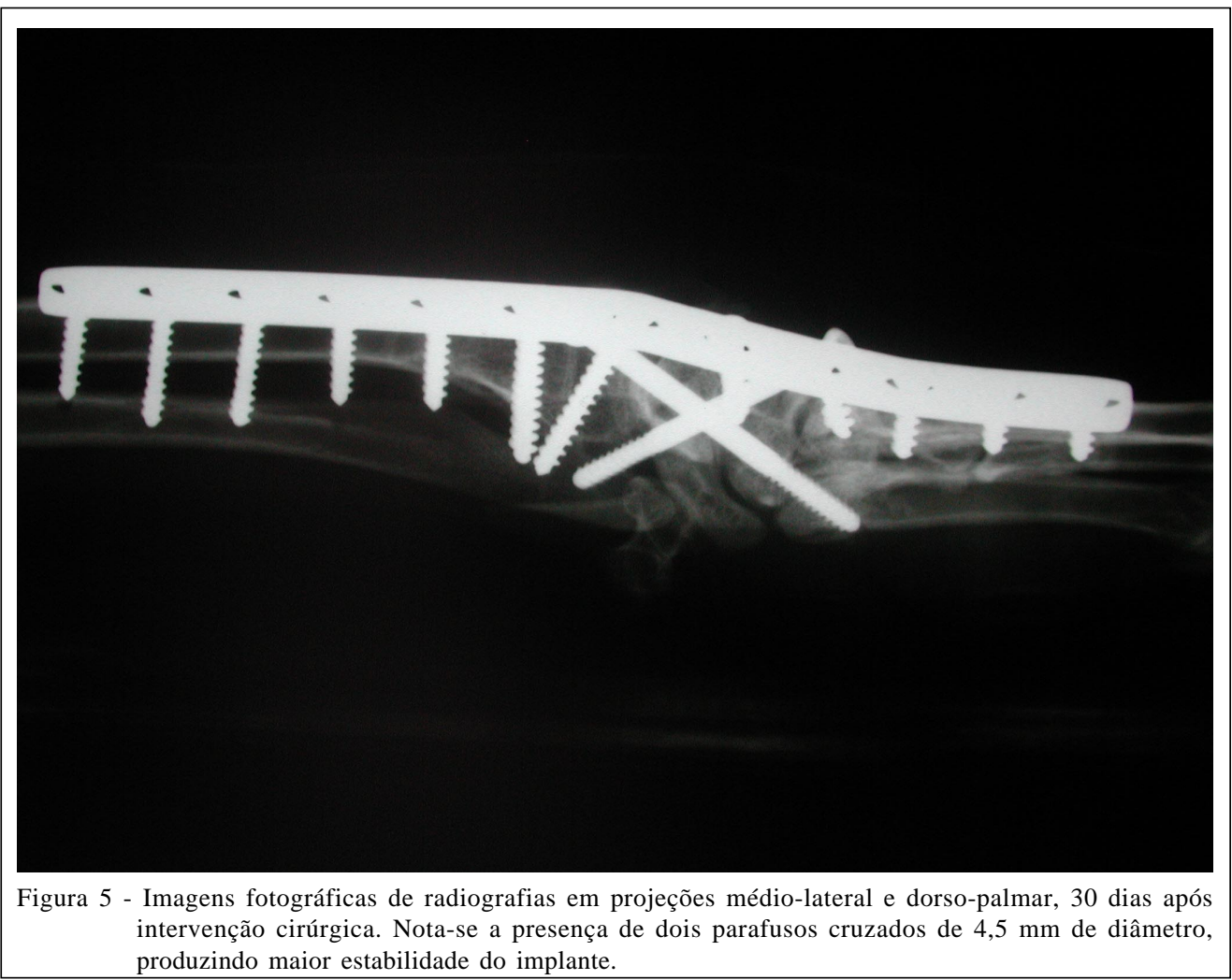

Ciência Rural, v.38, n.2, mar-abr, 2008. 
significativas, resultando em hiperextensão articular. Pode-se notar, neste estudo, a alta prevalência de casos em cães de raças grandes (94\% dos casos atendidos), conforme disposto na tabela 1 , sem nenhuma prevalência racial, em oposição ao proposto por DENNY \& BARR (1991), que indicaram certa predisposição dos cães do padrão Collie a desenvolverem hiperextensão carpal. A média de idade dos pacientes neste estudo foi de 6 anos, similar à encontrada por DENNY \& BARR (1991), cuja média foi de 5 anos, e por WILLER et al. (1990), com média de 5,8 anos.

Com relação à técnica utilizada, o acesso foi idêntico ao proposto por DENNY \& BARR (1991) e FLÜCKIGER \& SCHMÖKEL (2003), optando-se por placas de 3,5mm, por apresentarem maior segurança em relação à fixação, conforme proposto por JOHNSON (1980), DENNY \& BARR (1991), RALPHS et al. (2000) e MICHAL et al. (2003).
As complicações decorrentes deste procedimento, conforme citadas por LI et al. (1999), foram observadas em apenas dois pacientes (10\%), com exposição de parte da placa após algum tempo de cirurgia. As placas utilizadas apresentavam, no mínimo, sete parafusos, conforme sugeriram DENNY \& BARR (1991), respeitando a angulação de 10 graus existente entre o rádio e os metacarpos. Desta forma, previne-se fraturas de metacarpos, por se encobrir superfície superior a $50 \%$ do comprimento do osso citado, conforme apresentado por WHITELOCK et al. (1999), colaborando assim para o bom resultado na maioria dos casos deste estudo.

Nas publicações pesquisadas, não se relata o uso do material resultante da fresagem ou ostectomia como enxerto local, embora sejam conhecidas as propriedades osteocondutoras do osso cortical, quando utilizada em tratamentos de fraturas ou artrodeses. Deste modo, foi utilizada a enxertia como

Tabela 1 - Classificação dos casos estudados quanto a raça, idade, peso, sexo, tipo de artrodese (tamanho da placa e quantidade de parafusos) e complicações pós-cirúrgicas.

\begin{tabular}{|c|c|c|c|c|c|c|}
\hline $\begin{array}{l}\text { Numero do } \\
\text { caso }\end{array}$ & Raça & Idade & $\begin{array}{l}\text { Peso } \\
(\mathrm{kg})\end{array}$ & Sexo & Tamanho da placa & Complicações \\
\hline 1 & Doberman & 6 anos & 32 & $\mathrm{~F}$ & $3,5 \mathrm{~mm}$ com 8 furos & Ndn \\
\hline 2 & Rottweiler* & 3 anos & 41 & M & 3,5mm com 7 furos & Ndn \\
\hline 3 & Rottweiler ${ }^{*}$ & 3 anos & 41 & M & 3,5mm com 7 furos & Ndn \\
\hline 4 & Rottweiler ${ }^{*}$ & 7 anos & 43 & M & $3,5 \mathrm{~mm}$ com 7 furos & Ndn \\
\hline 5 & Rottweiler* & 7 anos & 43 & M & $3,5 \mathrm{~mm}$ com 7 furos & $\begin{array}{l}\text { Exposição de parte da placa após } 4 \text { meses de } \\
\text { cirurgia }\end{array}$ \\
\hline 6 & Pastor alemão & 11 anos & 31 & $\mathrm{~F}$ & 3,5mm com 9 furos & $\begin{array}{l}\text { Aumento de volume em região de carpos que } \\
\text { persistiu até os } 2 \text { meses de pós-cirúrgico }\end{array}$ \\
\hline 7 & Pastor alemão & 8 anos & 29 & $\mathrm{~F}$ & $3,5 \mathrm{~mm}$ com 7 furos & Animal não permitiu a manutenção do penso \\
\hline 8 & Srd & 5 anos & 19 & M & $3,5 \mathrm{~mm}$ com 7 furos & $\begin{array}{l}\text { Exposição de parte da placa após } 2 \text { meses de } \\
\text { cirurgia }\end{array}$ \\
\hline 9 & Fila & 8 anos & 38 & $\mathrm{~F}$ & 3,5mm com 9 furos & Ndn \\
\hline 10 & Srd & $\begin{array}{l}10 \\
\text { MESES }\end{array}$ & 29 & M & $3,5 \mathrm{~mm}$ com 7 furos & Ndn \\
\hline 11 & $\begin{array}{l}\text { Husky } \\
\text { siberiano }\end{array}$ & 9 anos & 27 & $\mathrm{~F}$ & $3,5 \mathrm{~mm}$ com 8 furos & Ndn \\
\hline 12 & Fila & 5 anos & 39 & M & $3,5 \mathrm{~mm}$ com 7 furos & Ndn \\
\hline 13 & Mastin & 11 anos & 48 & M & $3,5 \mathrm{~mm}$ com 10 furos & Ndn \\
\hline 14 & $\begin{array}{l}\text { Pastor } \\
\text { alemão* }\end{array}$ & 1 ano & 31 & $\mathrm{~F}$ & $3,5 \mathrm{~mm}$ com 8 furos & Ndn \\
\hline 15 & $\begin{array}{l}\text { Pastor } \\
\text { alemão }\end{array}$ & 1 ano & 31 & $\mathrm{~F}$ & $3,5 \mathrm{~mm}$ com 7 furos & Ndn \\
\hline 16 & $\begin{array}{l}\text { Pastor } \\
\text { alemão }\end{array}$ & 11 anos & 37 & M & $3,5 \mathrm{~mm}$ com 8 furos & Animal não permitiu a manutenção do penso \\
\hline 17 & $\begin{array}{l}\text { Pastor } \\
\text { alemão }\end{array}$ & 11 anos & 37 & M & $3,5 \mathrm{~mm}$ com 8 furos & Ndn \\
\hline 18 & Doberman & 7 anos & 30 & $\mathrm{~F}$ & $3,5 \mathrm{~mm}$ com 7 furos & Animal não permitiu a manutenção do penso \\
\hline 19 & Pastor alemão & 6 anos & 28 & M & 3,5mm com 8 furos & Ndn \\
\hline
\end{tabular}

*Procedimento cirúrgico bilateral; Ndn - nada digno de nota.

Ciência Rural, v.38, n.2, mar-abr, 2008. 
forma de maximizar os resultados e minimizar o tempo de recuperação.

Os resultados da artrodese total do carpo obtidos neste estudo, com fusão sólida da articulação em até 300 dias de pós-cirúrgico em $80 \%$ dos casos estudados, foram semelhantes aos descritos por DENNY \& BARR (1991), sendo que, em 68\% dos pacientes, a recuperação se deu sem qualquer complicação significativa. Pequenas complicações, como o aumento de volume ou a impossibilidade de manutenção da imobilização externa, foram observadas em $22 \%$ dos casos, não determinando qualquer alteração no resultado final. Em 10\% dos casos estudados, houve exposição da placa e conseqüente atraso na fusão articular.

A fusão articular foi estabelecida por meio de radiografias articulares em duas projeções, com ângulo de 90 graus entre si, uma dorso-palmar e uma médio-lateral.

Esta abordagem permitiu minimizar as dificuldades em definir a resposta osteoarticular destes processos, uma vez que a sobreposição da placa em relação aos ossos interfere na visibilização tanto de respostas satisfatórias em relação à fusão articular, quanto em relação a áreas de lise do osso subcondral adjacente à placa e ao aumento da interlinha radiográfica no espaço articular. Tais alterações, podem se formar devido a fatores como hipotrofia óssea decorrente de imobilização muito rígida (lei de Wolff), ou necrose térmica por remoção da cartilagem articular por meio de serra pneumática, conforme salientaram FLÜCKIGER \& SCHMÖKEL (2003). A remoção da placa é exeqüível após a articulação ter atingido escore 2 (fusão sólida), ativando assim a estabilidade final necessária para os processos de artrodese.

\section{REFERÊNCIAS}

BRINKER, W.O. et al. Handbook of small animal orthopedics and fracture repair. 3.ed. Philadelphia: Saunders, 1997. 743p.

DENNY, H.R.; BARR, A.R.S. Partial carpal and pancarpal arthrodesis in the dog: a review of 50 cases. Journal of Small Animal Practice, v.32, p.329-334, 1991.

FLÜCKIGER, U.M.; SCHMÖKEL, H. Healing of dorsal pancarpal arthrodesis in the dog. Journal of Small Animal Practice, v.44, p.109-112, 2003.

GUILLIARD, M.J.; MAYO, A.K. Subluxation/ luxation of the second carpal in two racing greyhounds and a staffordshire bull terrier. Journal of Small Animal Practice, v.42. p.356359, 2001

JOHNSON, K.A. Carpal arthrodesis in dogs. Australian Veterinary Journal, v.56, p.565-573, 1980.

LI, A. et al. Thirteen pancarpal arthrodeses using 2.7/ $3.5 \mathrm{~mm}$ hybrid dynamic compression plates. Veterinary Compendium of Orthopadics and Traumatology, v.12, p.102-107, 1999

MICHAL, U. et al. Healing of dorsal pancarpal arthrodesis in the dog. Journal of Small Animal Practice, v.44. p.109112, 2003.

RALPHS, S.C. et al. Idiopathic erosive polyarthritis in six dogs (description of the disease and treatment with bilateral pancarpa arthrodesis). Veterinary Compendium of Orthopadics and Traumatology, v.13, p.191-196, 2000.

TOMLIN, J.L. et al. Radial carpal bone fractures in dogs. Journal of the American Animal Hospital Association, v.37, p.173-178, 2001.

WILLER, R.L. et al. Partial carpal arthrodesis for third degree carpal sprains. a review of 45 carpi. Veterinary Surgery, v.19. n.5, p.334-340, 1990.

WHITELOCK, R.G. et al. Metacarpal fractures associated with pancarpal arthrodesis in dogs. Veterinary Surgery, v.28, p.25-30, 1999. 